\title{
Endonasal endoscopic pituitary surgery in the elderly
}

\author{
Peter J. Wilson, FRACS, ${ }^{1,2}$ Sacit B. Omay, MD, ${ }^{1}$ Ashutosh Kacker, MD, ${ }^{3}$ Vijay K. Anand, MD, ${ }^{3}$ and \\ Theodore H. Schwartz, MD1,3,4
}

\begin{abstract}
Departments of ${ }^{1}$ Neurosurgery, ${ }^{3}$ Otolaryngology, and ${ }^{4}$ Neuroscience, Weill Cornell Medical College, NewYork-Presbyterian Hospital, New York, New York; and 'Department of Neurosurgery, Prince of Wales Hospital, Sydney, New South Wales, Australia
\end{abstract}

OBJECTIVE Pituitary adenomas are benign, slow-growing tumors that cause symptoms either through mass effect or hormone overproduction. The decision to operate on a healthy young person is relatively straightforward. In the elderly population, however, the risks of complications may increase, rendering the decision more complex. Few studies have documented the risks of surgery using the endonasal endoscopic approach in a large number of elderly patients. The purpose of this study was to audit a single center's data regarding outcomes of purely endoscopic endonasal transsphenoidal resection of pituitary adenomas in elderly patients and to compare them to the current literature.

METHODS A retrospective review of a prospectively acquired database of all endonasal endoscopic surgeries done by the senior authors was queried for patients aged 60-69 years and for those aged 70 years or older. Demographic and radiographic preoperative data were reviewed. Outcomes with respect to extent of resection and complications were examined and compared with appropriate statistical tests.

RESULTS A total of 135 patents were identified ( 81 aged $60-69$ years and 54 aged 70 years or older [70+]). The average tumor diameter was slightly larger for the patients in the 70+ age group (mean [SD] $25.7 \pm 9.2 \mathrm{~mm}$ ) than for patients aged $60-69$ years $(23.1 \pm 9.8 \mathrm{~mm}, p=0.056)$. There was no significant difference in intraoperative blood loss $(p>0.99)$, length of stay ( $p=0.22)$, or duration of follow-up $(p=0.21)$ between the 2 groups. There was a $7.4 \%$ complication rate in patients aged 60-69 years ( 3 nasal and 3 medical complications) and an $18.5 \%$ complication rate in patients older than 70 years ( 4 cranial, 3 nasal, 1 visual, and 2 medical complications; $p=0.05$ overall and 0.013 for cranial complications). Cranial complications in the $70+$ age category included 2 postoperative hematomas, 1 pseudoaneurysm formation, and 1 case of symptomatic subdural hygromas.

CONCLUSIONS Endonasal endoscopic surgery in elderly patients is safe, but there is a graded increase in complication rates with increasing age. The decision to operate on an asymptomatic or mildly symptomatic patient in these age groups should take this increasing complication rate into account. The use of a lumbar drain or lumbar punctures should be weighed against the risk of subdural hematoma in patients with preexisting atrophy.

https://thejns.org/doi/abs/10.3171/2016.11.JNS162286

KEY WORDS adenoma; elderly; endonasal; endoscopic; pituitary surgery; transsphenoidal

$\mathrm{T}$ HE number of people aged 70 years or over in the United States is projected to increase from 29.2 million in 2012 to 63.6 million in $2050 .{ }^{30}$ In common surgical procedures, the majority of postsurgical deaths occur in patients 70 of age or older, ${ }^{32}$ with even greater risks in those aged 80 years and above. ${ }^{47}$ Whether this arbitrary age cutoff has the same negative prognostic correlation in benign intracranial pathology has not been clearly demonstrated. Pituitary tumors make up $12.9 \%$ of the primary intracranial neoplasms in the elderly, with an incidence of $18.1 / 100,000$ persons per year ${ }^{20}$ and an overall prevalence of $16.7 \%$.

The majority of pituitary tumors in the elderly are nonfunctional, ${ }^{27}$ and most of the incidental microadenomas are adrenocorticotropic hormone (ACTH) cell adenomas, followed by prolactin cell adenomas. ${ }^{22}$ Although the tumor volume doubling time is longer in older patients ${ }^{44}$ there is increased mortality in patients with pituitary disease..$^{42}$ If this pathology can be managed safely with surgical intervention, there is an argument that it should be offered

ABBREVIATIONS DDAVP = 1-desamino-8d-arginine vasopressin; GTR = gross-total resection; NTR = near-total resection; STR = subtotal resection.

SUBMITTED August 30, 2016. ACCEPTED November 17, 2016.

INCLUDE WHEN CITING Published online April 7, 2017; DOI: 10.3171/2016.11.JNS162286. 
to patients as an alternative to the natural history of the disease.

Nevertheless, non-hormone producing pituitary tumors are benign slow-growing tumors and cause morbidity primarily from mass effect. In the absence of symptoms, the decision to operate rests on a careful weighing of the risks and benefits of surgery. Several publications have outlined the risks of surgery in the elderly population using the operative microscope, but with the advent of the endonasal endoscopic approach, the risks of surgery may have changed. Few publications have examined the risks of endonasal endoscopic pituitary surgery in the elderly. Moreover, the age threshold has been variable, and it is unclear at what age the risks increase. In this study we had adequate numbers of patients to separately examine risks of surgery for patients in the 60- to 69-year age range and those 70 years of age or older to see if the additional decade makes a difference. These data should be useful in making decisions regarding offering surgery to patients in the age groups.

\section{Methods}

A retrospective review of a prospective database of all pituitary tumors resected with an endoscopic endonasal approach at Weill Cornell Medicine, NewYork-Presbyterian Hospital between January 2005 and April 2016 was performed. Institutional review board approval was obtained for this study. Patients were included if their age at the time of surgery was 60 years or greater.

The following data were collected: histology, maximum diameter of the tumor on the preoperative volumetric MRI scan, extent of resection as determined both by intraoperative assessment and radiologically on the postoperative MRI. Gross-total resection (GTR) was defined as no evidence of residual tumor; near-total resection (NTR) if 90\%-99\% of the tumor was resected; and subtotal resection (STR) if less than $90 \%$ of the tumor was resected. Operative blood loss, occurrence of intraoperative CSF leak, perioperative complications (subcategorized into cranial, nasal, visual, and medical), recurrence during follow-up, radiological signs of intracranial hypotension (subdural fluid collections, enhancement of meninges, or signs of brain sagging, ${ }^{40}$ such as increased distance of the top of the cerebral aqueduct from the incisural line ${ }^{37}$ and/ or tonsillar herniation), length of follow-up to most recent outpatient clinical review since surgery, and identification of pre- and postoperative hormone replacement therapy (hydrocortisone, thyroxine, and/or 1-desamino-8d-arginine vasopressin [DDAVP]). Prior surgery and/or radiation treatment was also noted.

Statistical analysis was completed using XLSTAT (Addinsoft), with the 2-tailed t-test to compare parametric data and the Mann-Whitney U-test to compare nonparametric data following the Shapiro-Wilks test for normality. Binary data were compared using the chi-square test. Box plots were created for the purpose of data presentation using a standard of 1 box plot per data series.

\section{Surgical Technique}

All operations were performed by a surgical team that included an otolaryngologist (V.K.A. or A.K.) and a neurosurgeon (T.H.S.) at the Institute for Minimally Invasive Skull Base and Pituitary Surgery. The details of surgical technique have been described previously. ${ }^{16}$ In addition to the routine endoscopic endonasal approach to the sella, a lumbar puncture is routinely performed under general anesthesia but prior to the endonasal approach to facilitate injection of intrathecal fluorescein $(0.2 \mathrm{ml}$ diluted with $10 \mathrm{ml}$ of CSF); steroids and diphenhydramine $50 \mathrm{mg}$ are also administered intravenously to decrease a potential inflammatory response to the fluorescein..$^{2,19,34,36,43}$ If a large CSF leak was expected (in cases of tumors with a vertical diameter $>20 \mathrm{~mm}$ with $>10 \mathrm{~mm}$ extension above the planum sphenoidale), then a lumbar drain is placed and postoperatively allowed to drain $5 \mathrm{ml} /$ hour until the second postoperative night, when it is removed. If the spinal subarachnoid space is unable to be entered at the time of surgery, then the lumbar puncture or drain is abandoned and the procedure continued as normal.

A binarial endonasal approach is routinely performed by the otolaryngologist, with harvest of a nasoseptal flap $^{13,29}$ for cases in which intraoperative CSF leak is expected (see above) and lateralization of the middle turbinates. Following broad exposure of the sphenoid sinus, including removal of the sphenoid rostrum to the base of the clivus, an endoscopic scope holder is used to secure the endoscope and allow the neurosurgeon to perform a 2-handed, single-surgeon opening of the sella turcica and resection of the tumor. The tumor is removed in a standard fashion, and a standard algorithm is used to close the sella. ${ }^{19,26,31}$

Postoperatively, patients are observed in the intensive care unit overnight prior to transfer to the neurosurgical ward the next day. A postoperative MRI scan with volumetric protocol, including pre- and postgadolinium spoiled gradient echo sequences, is performed on postoperative Day 1 or 2. If a lumbar drain is in situ, the MRI is performed the day following its removal at the earliest. Patients are discharged home following satisfactory review by the medical team and allied health professionals.

\section{Results}

A total of 135 patients were included in this study -81 patients between 60 and 69 years of age and 54 patients aged 70 years or older. Further demographics and details regarding sex, tumor type, intraoperative blood loss, length of stay, length of time until most recent follow-up, and tumor diameter are presented in Table 1.

Box plots of maximum tumor diameter in the 2 different age groups are presented in Fig. 1.

Perioperative complications were more common in the older age group, but the difference did not quite reach statistical significance. In the 60- to 69-year-old group there was a $7.4 \%$ complication rate $(6$ complications in 81 patients). Three of the complications were nasal (1 intraoperative cribriform plate fracture with associated CSF leak requiring repair, 1 mucocele requiring debridement, and 1 significant episode of epistaxis), and 3 were medical (1 case of postoperative seizures and 2 cases in which patients required readmission within 30 days of discharge 
TABLE 1. Summary of demographic and clinical characteristics of the study groups

\begin{tabular}{lccc}
\hline \multirow{2}{*}{ Characteristic } & \multicolumn{2}{c}{ Age Group } & \multirow{2}{c}{$p$} \\
\cline { 2 - 3 } & $60-69$ Yrs & $70+$ Yrs & Value \\
\hline No. of pts & 81 & 54 & \\
\hline Male sex & $42(52 \%)$ & $33(61 \%)$ & 0.29 \\
\hline Pathology & \multicolumn{3}{c}{-} \\
\hline Pituitary apoplexy & 2 & 4 & \\
\hline Cushing's disease & 8 & 3 & \\
\hline GH-secreting adenoma & 8 & 3 & \\
\hline Nonfunctioning adenoma & 60 & 42 & \\
\hline Prolactinoma & 2 & 2 & \\
\hline Other pituitary lesion & 1 & - & \\
\hline Blood loss (ml), mean & $54.5 \pm 75.4$ & $45.7 \pm 35.1$ & $>0.99$ \\
\hline LOS (days), mean & $3.1 \pm 1.3$ & $4.0 \pm 3.3$ & 0.22 \\
\hline Follow-up (mos), mean & $30.9 \pm 31.7$ & $22.5 \pm 24.6$ & 0.21 \\
\hline Tumor diameter (mm), mean & $23.1 \pm 9.8$ & $25.7 \pm 9.2$ & 0.056 \\
\hline
\end{tabular}

$\mathrm{GH}=$ growth hormone; $\mathrm{LOS}=$ length of stay; $\mathrm{pt}=$ patient.

Values are numbers of patients unless otherwise indicated. Means are given with standard deviations.

due to headaches that were able to be managed with simple analgesia). In the group of patients who were 70 years or older (the $70+$ group) there was an $18.5 \%$ complication rate (10 complications in 54 patients). Four of the complications were cranial (2 postoperative hematomas, 1 pseudoaneurysm formation, and 1 case of intracranial hypotension with bilateral subdural hematomas requiring evacuation), 3 were nasal (1 mucocele requiring debridement, 1 medpore extrusion requiring removal, and 1 case of significant postoperative epistaxis requiring intervention), 1 was visual (1 episode of visual loss without compression of the optic apparatus on postoperative imaging), and 2 were medical (1 pulmonary embolism and 1 case of pneumonia). Statistical significance was approached but not reached for the difference in the overall rate of complications $(\mathrm{p}=0.05)$; the between-groups difference in the rate of cranial complications, however, was statistically significant $(p=0.013)$. There were 2 incidental findings of radiological but asymptomatic intracranial hypotension in the $70+$ group (1 patient had small bilateral subdural hematomas after lumbar drain insertion and 1 had dural enhancement and descent of the top of the cerebral aqueduct below the incisural line post lumbar puncture), and 1 similar incidental finding in the 60- to 69-year-old group (mild tonsillar herniation post-lumbar drain insertion).

Intraoperative CSF leaks were identified in $25(46.3 \%)$ of the 54 patients aged 70 years or older and in $54(66.7 \%)$ of the 81 patients aged 60-69 years (significantly more likely in the younger age group; $p=0.019$ ). Six patients in each category were unable to have fluorescein administered intraoperatively, and 4 of these in each group were identified as having a CSF leak during surgery. However, there were no cases of postoperative CSF leak identified in either age category, let alone a leak requiring reoperation. Overall, the maximum tumor diameter was significantly larger in patients undergoing lumbar drainage than in

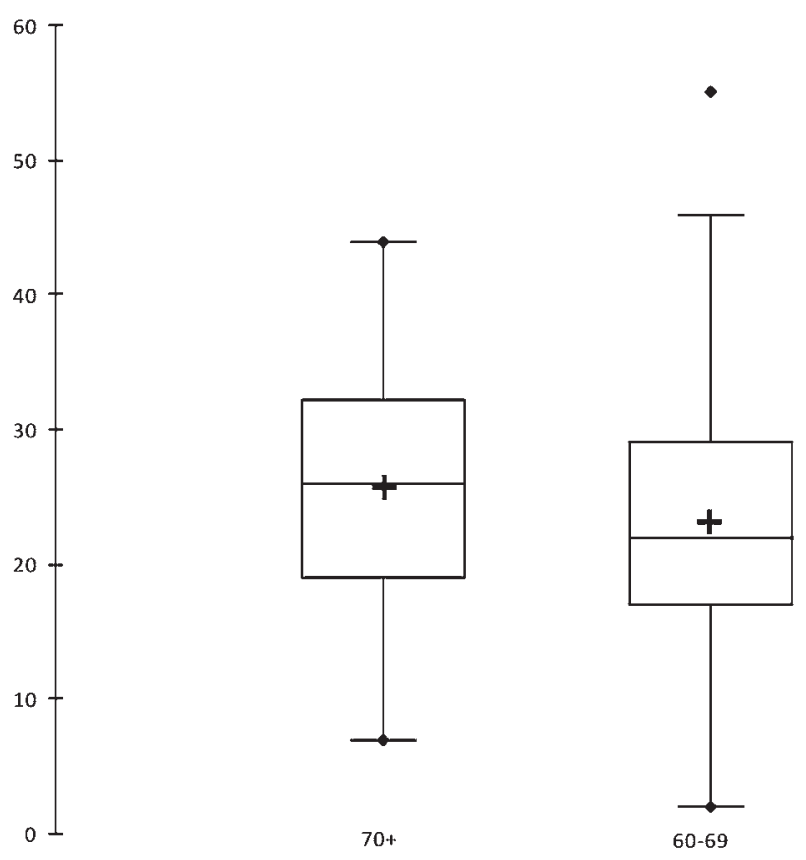

FIG. 1. Maximum tumor diameter $(\mathrm{mm})$ for patients aged $70+$ years versus those aged $60-69$ years. The boxes represent the interquartile ranges (IQRs), crosses correspond to means, central horizontal bars to medians, and the whiskers represent the minimum and maximum values excluding outliers. Points above or below the whiskers are considered outliers.

those who underwent lumbar puncture alone ( $\mathrm{p}<0.0001)$; these data were normally distributed for both samples. Patients who underwent lumbar drain insertion were significantly more likely to have an intraoperative leak $(\mathrm{p}=$ $0.002 ; 28$ [80\%] of 35 patients vs 44 [50\%] of 88 patients with lumbar puncture alone).

Box plots of maximum tumor diameter for all patients and subcategorized by age compared with lumbar drain placement or lumbar puncture are presented in Figs. 2 and 3 , respectively.

New hormone deficits requiring any form of replacement were present in 10 patients aged 60-69 years and 11 patients aged 70 years or older (no significant difference, $\mathrm{p}=0.208$ ). Cortisol was the most commonly deficient hormone requiring replacement ( 8 patients in each age group), followed by thyroxine (5 patients aged 60-69 and 7 patients aged 70+) and vasopressin (with diabetes insipidus requiring DDAVP treatment in 4 patients aged 60-69 and 2 patients aged $70+$ ).

The rates of radiographically confirmed GTR, NTR, and STR were $70.4 \%, 20.7 \%$, and $8.9 \%$ for the whole group $-64.8 \%, 29.6 \%$, and $5.6 \%$ for the patients 70 years or older and $74.1 \%, 14.8 \%$, and $11.1 \%$ for the patients aged 60-69 years. Recurrence occurred in 4 cases in each age category. In the 70+ age group, the intraoperative macroscopic assessment was GTR in all 4 patients, with GTR being confirmed on postoperative MRI in 2 of the 4 patients. There were 4 patients in this age group who had STR and 10 patients who had NTR, and none of these patients had a clinically relevant recurrence within the follow-up period. Three of the 4 patients who underwent STR and all of those who underwent NTR had a preoperative maximum 


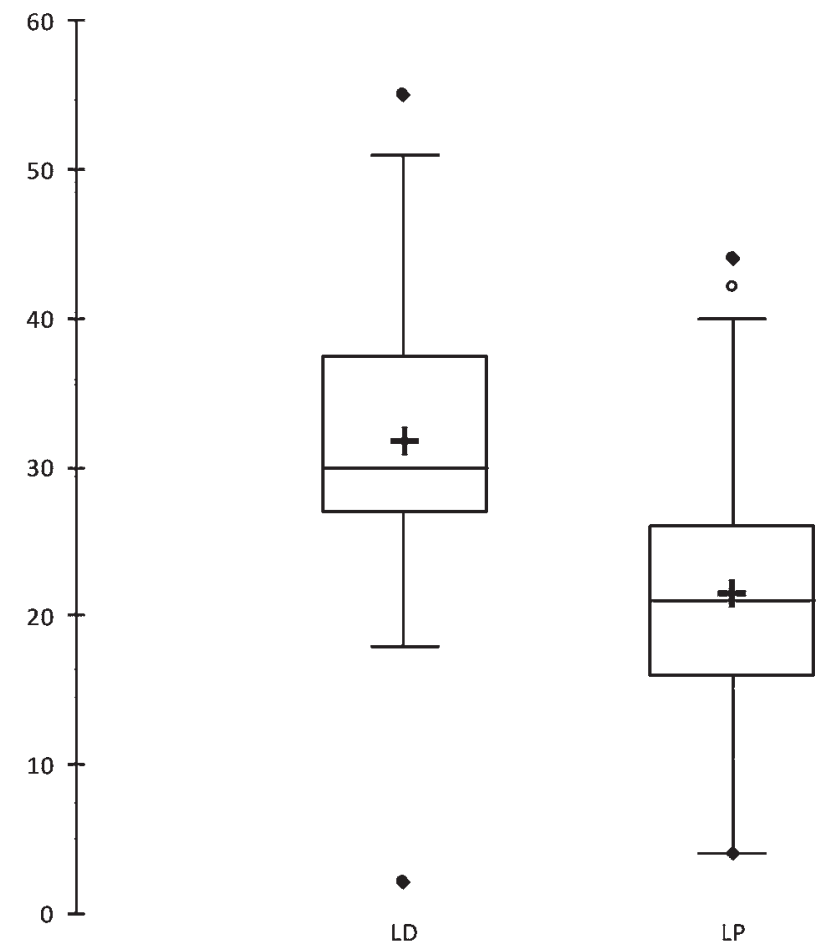

FIG. 2. Maximum tumor diameter $(\mathrm{mm})$ for all patients with lumbar drains (LD) compared with lumbar puncture (LP). The boxes represent IQRs, crosses correspond to means, central horizontal bars to medians, and the whiskers represent the minimum and maximum values excluding outliers. Points above or below the whiskers are considered outliers.

tumor diameter $>10 \mathrm{~mm}$ (mean $30.4 \mathrm{~mm}$, range $8-44$ $\mathrm{mm}$ ). Results were similar in the 60- to 69-year-old group; in 3 of the 4 patients with subsequent tumor recurrence, the resection was assessed intraoperatively as GTR, and in 2 of these 3 cases GTR was confirmed on postoperative MRI. In the fourth case, the intraoperative assessment was NTR, but the radiological assessment was STR. An additional 2 patients had NTR and 7 STR based on postoperative MRI; however, none of these patients were found to have any clinically relevant recurrence on further follow-up. All patients in this group who underwent subtotal or near-total resection had a maximum tumor diameter greater than $10 \mathrm{~mm}$ (mean $32.2 \mathrm{~mm}$, range 17-51 $\mathrm{mm}$ ). The time to recurrence was similar in the 2 groups -3.5 , $7.5,39.2$, and 59 months for the 4 patients who had recurrence and were older than 70 years at the time of surgery and 2.9, 3.8, 63.9, and 82 months for the 4 patients who had recurrence and were 60-69 years old at the time of surgery.

Ten of the patients in the 60- to 69-year-old group had undergone previous surgery for their pituitary lesion, and 1 of these patients had previously received radiation treatment. Three of the patients in the $70+$ group had undergone previous pituitary surgery, and 2 of these patients had also received prior irradiation of their lesion. This difference was not statistically significant $(\mathrm{p}=0.19)$, and there was only 1 postoperative complication among the patients who were undergoing repeat surgery (a sphenoid mucocele requiring debridement in a 72-year-old who had also had prior irradiation).

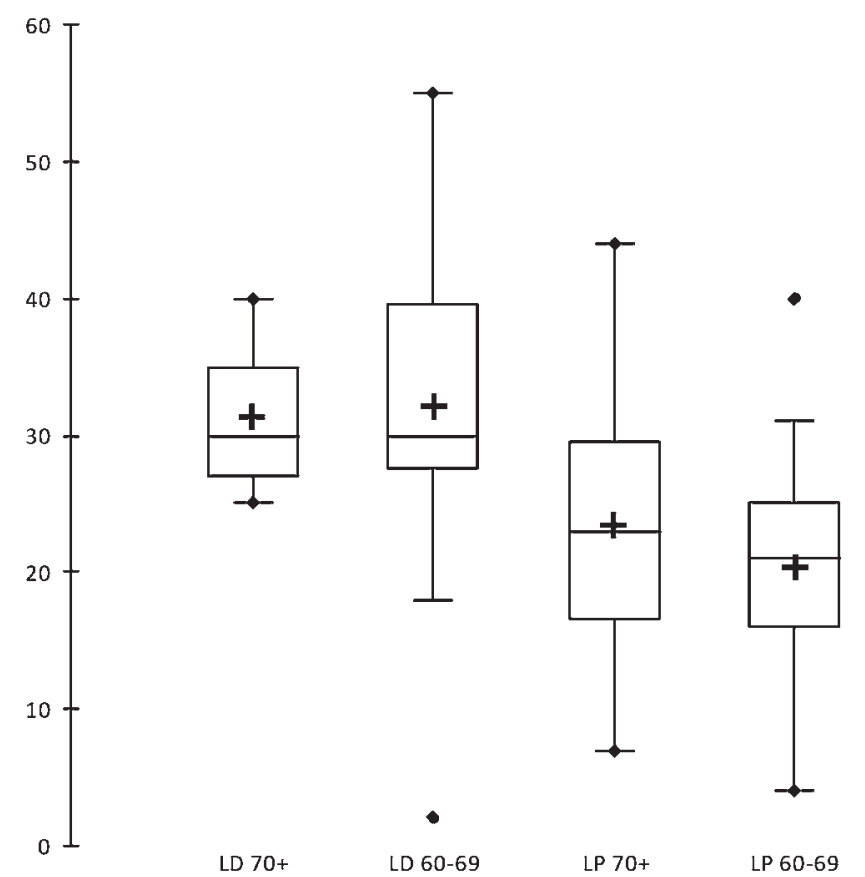

FIG. 3. Maximum tumor diameter $(\mathrm{mm})$ for patients subcategorized by age with lumbar drains (LD) compared with lumbar puncture (LP). The boxes represent IQRs, crosses correspond to means, central horizontal bars to medians, and the whiskers represent the minimum and maximum values excluding outliers. Points above or below the whiskers are considered outliers.

\section{Discussion}

A comprehensive understanding of complication rates in elderly patients undergoing transsphenoidal surgery for pituitary adenomas is essential because these slow-growing benign tumors can often be managed with observation. The decision to operate may incur risks in the elderly population, and intervention must be justified based on a careful calculation of the risk-to-benefit ratio. Our data show a modest increase in complications in patients older than 70 years compared with those 60-69 years of age, but of particular note is the significantly larger risk of cranial complications, although still uncommon, in the older age group. As this was a retrospective series, it was not possible to prospectively power our series in regard to patient numbers to potentially identify other discrepancies between the 2 age groups. We are, nonetheless, able to reach the following conclusion. For patients aged 60-69 years, treatment algorithms can be used that are similar to those used for younger patients since the risks are quite low. However, for patients older than 70 years the decision to operate requires a more careful weighing of the risks and benefits, and perhaps only symptomatic patients, or those with more rapidly growing tumors, should be treated surgically.

The published literature on transsphenoidal resections of pituitary adenomas in the elderly supports these conclusions (Table 2). However, the majority of reported series are from the era of microscopic surgery, with only 4 series identified as being purely endoscopic. Moreover, many of these papers have only limited numbers of patients, and the threshold for considering patients as elderly 
TABLE 2. Previously published series of elderly patients undergoing surgery for pituitary tumors

\begin{tabular}{|c|c|c|c|c|c|c|c|c|}
\hline Authors \& Year & Approach & $\begin{array}{l}\text { Pt Age } \\
(y r s)^{*}\end{array}$ & $\begin{array}{l}\text { No. of } \\
\text { Pts† }\end{array}$ & Pathology & $\begin{array}{l}\text { Postop } \\
\text { HR }\end{array}$ & Complications & $\begin{array}{l}\text { LOS } \\
\text { (days) }\end{array}$ & Mortality \\
\hline Benbow et al., 1997 & Unspecified & $65+$ & 32 & $4 \mathrm{G}, 27 \mathrm{~N}, 1 \mathrm{P}$ & Unspecified & $15.6 \% ; 3$ cranial, 1 med, 1 visual & - & $3.1 \%$ \\
\hline Minniti et al., 2001 & Unspecified & $65+$ & 22 & $22 \mathrm{G}$ & $13.6 \%$ & $318.1 \% ; 4$ cranial & $8.4 \pm 2.2$ & $0 \%$ \\
\hline Ferrante et al., 2002 & Unspecified & $70+$ & 39 & $5 \mathrm{G}, 31 \mathrm{~N}, 3 \mathrm{P}$ & $20.5 \%$ & $20.5 \% 1$ cranial, 1 med, 1 visual & $11.6 \pm 3.1$ & $0 \%$ \\
\hline Del Monte et al., 2007 & Unspecified & $65+$ & 23 & $23 \mathrm{~N}$ & $48 \%$ & $0 \%$ & - & $0 \%$ \\
\hline Hong et al., 2008 & Unspecified & $65+$ & 103 & $2 \mathrm{C}, 10 \mathrm{G}, 75 \mathrm{~N}, 16 \mathrm{P}$ & $10.7 \%$ & $6.8 \% ; 5$ cranial, 2 visual & $12.8 \pm 3.5$ & $0 \%$ \\
\hline Arita et al., 2008 & Unspecified & $65+$ & 7 & $7 \mathrm{G}$ & $0 \%$ & $0 \%$ & - & $0 \%$ \\
\hline Foppiani et al., 2008 & Unspecified & $65+$ & 8 & $1 \mathrm{G}, 7 \mathrm{~N}$ & $25 \%$ DI & $0 \%$ & - & $0 \%$ \\
\hline Rogne et al., 2009 & Unspecified & $70+$ & 33 & Unspecified & Unspecified & $0 \%$ & - & $0 \%$ \\
\hline Grossman et al., 2010 & Unspecified & $65+$ & 8400 & Unspecified & $3.5 \%$ & $32.6 \% ; 5.4 \%$ cranial, $22.5 \%$ med & 8.5 & $3.8 \%$ \\
\hline Danilowicz et al., 2013 & Unspecified & $65+$ & 33 & $\begin{array}{l}3 \mathrm{C}, 4 \mathrm{G}, 17 \mathrm{~N}, 5 \mathrm{O} \\
\quad 3 \mathrm{P}, 1 \mathrm{U}\end{array}$ & $87.9 \%$ & $57.9 \%$ & 10.4 & $3 \%$ \\
\hline Robenshtok et al., 2014 & Unspecified & $65+$ & 32 & $3 \mathrm{~A}, 29 \mathrm{~N}$ & $3.1 \%$ & $0 \%$ & - & $0 \%$ \\
\hline Cohen et al., 1989 & Microscopic & $70+$ & 12 & $1 \mathrm{~A}, 2 \mathrm{G}, 8 \mathrm{~N}, 10$ & $0 \%$ & $16.7 \% ; 2$ visual & - & $0 \%$ \\
\hline Puchner et al., 1995 & Microscopic & $65+$ & 15 & $15 \mathrm{G}$ & $0 \%$ & $6.7 \% ; 1$ nasal & $10.2 \pm 2.3$ & $0 \%$ \\
\hline Turner et al., 1999 & Microscopic & $65+$ & 58 & $\begin{array}{l}6 \mathrm{~A}, 6 \mathrm{G}, 2 \mathrm{C}, 38 \mathrm{~N} \\
\quad 4 \mathrm{O}, 2 \mathrm{P}\end{array}$ & $6.9 \% \mathrm{DI}$ & $19 \% ; 2$ cranial, 3 med, 5 visual & - & $0 \%$ \\
\hline Fraioli et al., 1999 & Microscopic & $70+$ & 11 & $1 \mathrm{C}, 1 \mathrm{G}, 8 \mathrm{~N}, 1 \mathrm{P}$ & $9.1 \% \mathrm{DI}$ & $9.1 \% ; 1$ med & 17 & $0 \%$ \\
\hline Kurosaki et al., 2001 & Microscopic & $70+$ & 32 & $32 \mathrm{~N}$ & $15.6 \%$ & $9.4 \% ; 3$ cranial & 16.3 & $0 \%$ \\
\hline Sheehan et al., 2008 & Microscopic & $70+$ & 64 & $3 \mathrm{G}, 61 \mathrm{~N}$ & $12.5 \%$ & $1.6 \% ; 1$ med & 2.6 & $0 \%$ \\
\hline Locatelli et al., 2013 & Microscopic & $65+$ & 43 & $5 \mathrm{~A}, 8 \mathrm{C}, 4 \mathrm{G}, 26 \mathrm{~N}$ & $9.3 \%$ & $27.9 \%$ & $5 \pm 2$ & $0 \%$ \\
\hline Liu et al., 2015 & Microscopic & $65+$ & 69 & $2 \mathrm{~A}, 7 \mathrm{C}, 4 \mathrm{G}, 56 \mathrm{~N}$ & $4.3 \%$ & $4.5 \% ; 1$ cranial, 2 med & $6.4 \pm 1.9$ & $1.5 \%$ \\
\hline Yunoue et al., 2014 & Combined $\rrbracket$ & $80+$ & 10 & $1 \mathrm{G}, 9 \mathrm{~N}$ & $0 \%$ & $0 \%$ & $11.5 \pm 3.6$ & $0 \%$ \\
\hline Pereira et al., 2014 & Both $^{* *}$ & $70+$ & 96 & $\begin{array}{l}12 \mathrm{~A}, 3 \mathrm{C}, 3 \mathrm{G}, 70 \mathrm{~N} \\
7 \mathrm{O}, 1 \mathrm{P}\end{array}$ & $20.9 \%$ & $\begin{array}{l}55.2 \% ; 2 \text { cranial, } 29 \text { med, } 13 \\
\text { nasal, } 9 \text { visual }\end{array}$ & 4 & $0 \%$ \\
\hline Hasegawa et al., 2011 & Endoscopic & $80+$ & 3 & $3 \mathrm{~A}$ & $0 \%$ & $0 \%$ & - & $0 \%$ \\
\hline Marenco et al., 2015 & Endoscopic & $65+$ & 25 & $25 \mathrm{~N}$ & $12 \%$ & $32 \% ; 7$ med, 1 nasal & 6.7 & $3.6 \%$ \\
\hline Gondim et al., 2015 & Endoscopic & $70+$ & 55 & $6 \mathrm{~A}, 49 \mathrm{~N}$ & $16.4 \%$ & $27.3 \% ; 8$ cranial, 6 med, 1 nasal & 8 & $1.8 \%$ \\
\hline Zhan et al., 2015 & Endoscopic & $65+$ & 158 & $158 \mathrm{~N}$ & $13.9 \%$ & $6.3 \% ; 7$ cranial, 3 med & - & 0 \\
\hline
\end{tabular}

$\mathrm{A}=$ apoplexy $\mathrm{C}=$ Cushing's disease; $\mathrm{DI}=$ diabetes insipidus; $\mathrm{G}=$ growth-hormone-secreting adenoma; med = medical; $\mathrm{N}=$ nonfunctioning pituitary adenoma; $\mathrm{O}=$ other; $\mathrm{P}=$ prolactinoma, $\mathrm{U}=$ unspecified.

* Age of patients defined as elderly.

$\dagger$ Number of patients reported in the elderly category.

$\ddagger$ Postoperative rate of new hormone replacement reported.

$\S$ Complications = complications reported excluding hormonal deficiency.

Tा Endoscopically assisted microscopic.

** Series included microscopic and endoscopic cases.

is inconsistent. Gondim et al. ${ }^{11}$ presented a similar study to ours with an identical definition of elderly (age at least 70 years) and compared 55 elderly patients with 30 patients aged 60-69 years and 289 patients younger than 60 years, all with nonfunctional pituitary adenomas. They found a higher rate of complications in the elderly group (32.7\%), compared with patients aged under 60 years (complications in 10\%). Similar to our findings in the present series, they found no difference in extent of resection or duration of hospitalization. Zhan et al. ${ }^{49}$ reviewed 158 cases involving patients aged 65 years and older, comparing them to 155 cases involving patients aged $40-55$ years. In contrast to our results and those of Gondim et al., the analysis of Zhan et al. showed equivalent complication rates in both groups $(6.3 \%$ in the elderly group and $5.7 \%$ in the younger group; both groups had 7 cranial complications each [6
CSF leaks and 1 postoperative hematoma], and the older group had 3 cases of meningitis compared with 2 cases in the younger group; $\mathrm{p}=0.85$ ). Marenco et al. ${ }^{25}$ reported on 25 patients aged 65 years or older who underwent a total of 28 endoscopic procedures for nonfunctioning pituitary adenomas, but the authors did not provide any data for younger patients managed at their center. There was one perioperative death in their series $(3.6 \%$ of 28 procedures), and complications were identified in 8 (32\%) of the 25 patients. Hasegawa et al..$^{14}$ reported a small case series of 3 patients who all had presented with apoplexy over the age of 80 years, and while the outcome for all 3 patients was excellent, it is not possible to draw any strong conclusions from their study. Yunoue et al. ${ }^{48}$ assessed 10 cases involving patients aged at least 80 years old who underwent endoscopically assisted microscopic resection of 
their pituitary tumors; the authors did not include a control group, but they reported excellent results overall with no complications. Pereira et al..$^{33}$ reviewed 106 consecutive procedures in 104 patients aged 70 years or older; they included a transition from microscopic surgery to endoscopic surgery within their series but did not subcategorize their results by approach and also had no control group from their own center. None of the other studies identified had sufficient numbers to divide the patients into separate groups, as we did, in order to examine the progressive increase in complications with increasing age. Our results are consistent with previous studies that show that while morbidity and mortality remain relatively low, there is a trend toward increased risk with increasing age. Our study is unique in being one of the largest studies to date and also comparing different elderly age groups as opposed to comparing single "elderly" group and a younger group. The unique study design allows us to differentiate between patients in the 60- to 69-year-old category and the 70+ category.

\section{Visual Changes}

Postoperative visual changes from ischemia seem to be a rare but possible complication in the elderly. In our series, 1 patient had visual deterioration not attributed to postoperative neural compression by a hematoma or an alternative mass lesion; in this case, the deterioration was attributed to an ischemic event. Cohen et al. ${ }^{4}$ reported visual deterioration in 2 patients following transsphenoidal pituitary surgery. A postoperative hematoma was identified in one of the 2 patients, and the patient's vision improved after the hematoma was evacuated, but the second patient had no hematoma and was presumed to have chiasmal ischemia. Turner et al. ${ }^{46}$ reported visual deterioration without evidence of hematoma in 3 of 60 elderly patients who underwent transsphenoidal pituitary surgery. Thus, it is pertinent to consider that elderly patients may be at increased risk of postoperative visual deterioration independent of surgical technique, although the reported numbers currently remain too small for statistical significance. The reason for this increase is likely related to atherosclerosis of small vessels feeding the chiasm, which are more susceptible to mechanical vasospasm.

\section{Intracranial Hypotension}

Use of lumbar drainage in the elderly, in the setting of cortical atrophy and larger subarachnoid spaces, needs to be approached with caution, as the risk of developing a subsequent subdural hematoma is higher in these patients. There was only 1 symptomatic case of intracranial hypotension that required operative intervention in our series, although there were 3 more cases that were incidentally noted on postoperative imaging and did not progress or require any intervention. This risk of subdural hematoma formation and intracranial hypotension has to be weighed against the potential benefits in reduction of postoperative CSF leaks. A randomized controlled trial performed by Zwagerman et al. ${ }^{50}$ regarding preemptive lumbar drain placement compared with no drain placement for extended endonasal surgery had to be stopped early, as the leak rate was overwhelmingly less in the lumbar drainage group in cases at higher risk of CSF leakage (extensive arachnoid dissection, dissection into a ventricle or cistern, and dural defect greater than $1 \mathrm{~cm}$ ). The statistically significant difference in tumor size for those patients in our series who underwent drain placement is expected given the indication for drain placement of a minimum vertical tumor diameter with extension above the planum sphenoidale, but this is also confirmed as an appropriate indication given the significant risk of intraoperative CSF leak in the lumbar drain category. The absence of cases requiring revision for ongoing postoperative CSF leakage in our series despite an intraoperative leak rate over $50 \%$ cannot be retrospectively confirmed to be solely related to lumbar drain placement. Nonetheless, it could be hypothesized as a potential contributing factor, in addition to meticulous closure. The risks of intracranial hypotension are increased by using a larger bore needle ${ }^{18}$ although a larger-bore Tuohy needle is necessary for safe lumbar drain placement. Furthermore, cases of life-threatening intracranial hypotension following lumbar drain placement have been reported, ${ }^{15}$ although the condition may be managed with an epidural blood patch..$^{45}$ In short, lumbar puncture and lumbar drainage can largely be used as a safe adjunct in endoscopic skull base surgery, but there are potential risks, particularly in the elderly population with increased brain atrophy. For elderly patients with significant brain atrophy our threshold for placing a lumbar drain is higher, and we place them primarily in cases of giant macroadenomas in which a high-flow leak is expected postoperatively.

\section{Conclusions}

Although the risks are slightly increased in patients over the age of 70 years, endoscopic endonasal pituitary surgery is still a very safe procedure. The use of a lumbar drain or lumbar punctures may increase the risk of subdural hematoma and should be considered with caution in patients with atrophic brains. In considering whether to recommend surgery for elderly patients with pituitary adenomas, the benign, slow-growing nature of the lesions makes the decision-making process challenging, and the risks of surgery should be weighed closely against the existence of likelihood of developing symptoms.

\section{References}

1. Arita K, Hirano H, Yunoue S, Fujio S, Tominaga A, Sakoguchi T, et al: Treatment of elderly acromegalics. Endocr J 55:895-903, 2008

2. Banu MA, Kim JH, Shin BJ, Woodworth GF, Anand VK, Schwartz TH: Low-dose intrathecal fluorescein and etiologybased graft choice in endoscopic endonasal closure of CSF leaks. Clin Neurol Neurosurg 116:28-34, 2014

3. Benbow SJ, Foy P, Jones B, Shaw D, MacFarlane IA: Pituitary tumours presenting in the elderly: management and outcome. Clin Endocrinol (Oxf) 46:657-660, 1997

4. Cohen DL, Bevan JS, Adams CB: The presentation and management of pituitary tumours in the elderly. Age Ageing 18:247-252, 1989

5. Danilowicz K, Ase E, Manavela M, Tobin S, Mana D, Abbati SG, et al: MON-168: Pituitary disease in elderly patients, presented at the Endocrine Society 95th Annual Meeting, June 15-18, 2013, San Francisco (Abstract) (http://press.endocrine. 
org/doi/10.1210/endo-meetings.2013.NP.7.MON-168) [Accessed January 19, 2017]

6. Del Monte P, Foppiani L, Ruelle A, Andrioli G, Bandelloni $\mathrm{R}$, Quilici P, et al: Clinically non-functioning pituitary macroadenomas in the elderly. Aging Clin Exp Res 19:34-40, 2007

7. Ezzat S, Asa SL, Couldwell WT, Barr CE, Dodge WE, Vance ML, et al: The prevalence of pituitary adenomas: a systematic review. Cancer 101:613-619, 2004

8. Ferrante L, Trillò G, Ramundo E, Celli P, Jaffrain-Rea ML, Salvati M, et al: Surgical treatment of pituitary tumors in the elderly: clinical outcome and long-term follow-up. J Neurooncol 60:185-191, 2002

9. Foppiani L, Ruelle A, Bandelloni R, Quilici P, Del Monte P: Hypopituitarism in the elderly: multifaceted clinical and biochemical presentation. Curr Aging Sci 1:42-50, 2008

10. Fraioli B, Pastore FS, Signoretti S, De Caro GM, Giuffrè R: The surgical treatment of pituitary adenomas in the eighth decade. Surg Neurol 51:261-267, 1999

11. Gondim JA, Almeida JP, de Albuquerque LA, Gomes E, Schops M, Mota JI: Endoscopic endonasal transsphenoidal surgery in elderly patients with pituitary adenomas. J Neurosurg 123:31-38, 2015

12. Grossman R, Mukherjee D, Chaichana KL, Salvatori R, Wand G, Brem H, et al: Complications and death among elderly patients undergoing pituitary tumour surgery. Clin Endocrinol (Oxf) 73:361-368, 2010

13. Hadad G, Bassagasteguy L, Carrau RL, Mataza JC, Kassam A, Snyderman CH, et al: A novel reconstructive technique after endoscopic expanded endonasal approaches: vascular pedicle nasoseptal flap. Laryngoscope 116:1882-1886, 2006

14. Hasegawa Y, Yano S, Sakurama T, Ohmori Y, Kawano T, Morioka M, et al: Endoscopic surgical treatment for pituitary apoplexy in three elderly patients over the age of 80 . Acta Neurochir Suppl 111:429-433, 2011

15. Hirono S, Kawauchi D, Higuchi Y, Setoguchi T, Kihara K, Horiguchi K, et al: Life-Threatening Intracranial Hypotension after Skull Base Surgery with Lumbar Drainage. J Neurol Surg Rep 76:e83-e86, 2015

16. Hofstetter C, Anand VK, Schwartz TH: Endoscopic transsphenoidal pituitary surgery. Oper Tech Otolaryngol 22:206-214, 2011

17. Hong J, Ding X, Lu Y: Clinical analysis of 103 elderly patients with pituitary adenomas: transsphenoidal surgery and follow-up. J Clin Neurosci 15:1091-1095, 2008

18. Hulou MM, Abd-El-Barr MM, Gormley WB, Zamani AA, Dunn IF, Al-Mefty O: The frequency and severity of intracranial hypotension post-intraoperative lumbar drainage using a Tuohy needle and the traditional needle. Br J Neurosurg 30:438-443, 2016

19. Jakimovski D, Bonci G, Attia M, Shao H, Hofstetter C, Tsiouris AJ, et al: Incidence and significance of intraoperative cerebrospinal fluid leak in endoscopic pituitary surgery using intrathecal fluorescein. World Neurosurg 82:e513e523, 2014

20. Kuratsu J, Ushio Y: Epidemiological study of primary intracranial tumours in elderly people. J Neurol Neurosurg Psychiatry 63:116-118, 1997

21. Kurosaki M, Lüdecke DK, Flitsch J, Saeger W: Surgical treatment of clinically nonsecreting pituitary adenomas in elderly patients. Neurosurgery 47:843-849, 2000

22. Kurosaki M, Saeger W, Luidecke DK: Pituitary tumors in the elderly. Pathol Res Pract 197:493-497, 2001

23. Liu J, Li C, Xiao Q, Gan C, Chen X, Sun W, et al: Comparison of pituitary adenomas in elderly and younger adults: clinical characteristics, surgical outcomes, and prognosis. J Am Geriatr Soc 63:1924-1930, 2015

24. Locatelli M, Bertani G, Carrabba G, Rampini P, Zavanone M, Caroli M, et al: The trans-sphenoidal resection of pitu- itary adenomas in elderly patients and surgical risk. Pituitary 16:146-151, 2013

25. Marenco HA, Zymberg ST, de Paula Santos R, Ramalho CO: Surgical treatment of non-functioning pituitary macroadenomas by the endoscopic endonasal approach in the elderly. Arq Neuropsiquiatr 73:764-769, 2015

26. Mascarenhas L, Moshel YA, Bayad F, Szentirmai O, Salek AA, Leng LZ, et al: The transplanum transtuberculum approaches for suprasellar and sellar-suprasellar lesions: avoidance of cerebrospinal fluid leak and lessons learned. World Neurosurg 82:186-195, 2014

27. Minniti G, Esposito V, Piccirilli M, Fratticci A, Santoro A, Jaffrain-Rea ML: Diagnosis and management of pituitary tumours in the elderly: a review based on personal experience and evidence of literature. Eur J Endocrinol 153:723-735, 2005

28. Minniti G, Jaffrain-Rea ML, Esposito V, Santoro A, Moroni C, Lenzi J, et al: Surgical treatment and clinical outcome of GH-secreting adenomas in elderly patients. Acta Neurochir (Wien) 143:1205-1211, 2001

29. Nyquist GG, Anand VK, Singh A, Schwartz TH: Janus flap: bilateral nasoseptal flaps for anterior skull base reconstruction. Otolaryngol Head Neck Surg 142:327-331, 2010

30. Ortman J, Velkoff V, Hogan H: An Aging Nation: The Older Population in the United States. Washington, DC: US Census Bureau, 2014 (http://www.census.gov/prod/2014pubs/ p25-1140.pdf). [Accessed January 19, 2017]

31. Patel KS, Komotar RJ, Szentirmai O, Moussazadeh N, Raper DM, Starke RM, et al: Case-specific protocol to reduce cerebrospinal fluid leakage after endonasal endoscopic surgery. J Neurosurg 119:661-668, 2013

32. Pedersen T, Eliasen K, Henriksen E: A prospective study of mortality associated with anaesthesia and surgery: risk indicators of mortality in hospital. Acta Anaesthesiol Scand 34:176-182, 1990

33. Pereira EA, Plaha P, Chari A, Paranathala M, Haslam N, Rogers A, et al: Transsphenoidal pituitary surgery in the elderly is safe and effective. Br J Neurosurg 28:616-621, 2014

34. Placantonakis DG, Tabaee A, Anand VK, Hiltzik D, Schwartz TH: Safety of low-dose intrathecal fluorescein in endoscopic cranial base surgery. Neurosurgery 61 (3 Suppl):161-166, 2007

35. Puchner MJ, Knappe UJ, Lüdecke DK: Pituitary surgery in elderly patients with acromegaly. Neurosurgery 36:677-684, 1995

36. Raza SM, Banu MA, Donaldson A, Patel KS, Anand VK, Schwartz TH: Sensitivity and specificity of intrathecal fluorescein and white light excitation for detecting intraoperative cerebrospinal fluid leak in endoscopic skull base surgery: a prospective study. J Neurosurg 124:621-626, 2016

37. Reich JB, Sierra J, Camp W, Zanzonico P, Deck MD, Plum F: Magnetic resonance imaging measurements and clinical changes accompanying transtentorial and foramen magnum brain herniation. Ann Neurol 33:159-170, 1993

38. Robenshtok E, Benbassat CA, Hirsch D, Tzvetov G, Cohen ZR, Iraqi HM, et al: Clinical course and outcome of nonfunctioning pituitary adenomas in the elderly compared with younger age groups. Endocr Pract 20:159-164, 2014

39. Rogne SG, Konglund A, Meling TR, Scheie D, Johannesen TB, Rønning P, et al: Intracranial tumor surgery in patients $>70$ years of age: is clinical practice worthwhile or futile? Acta Neurol Scand 120:288-294, 2009

40. Schievink WI, Maya MM, Louy C, Moser FG, Tourje J: Diagnostic criteria for spontaneous spinal CSF leaks and intracranial hypotension. AJNR Am J Neuroradiol 29:853-856, 2008

41. Sheehan JM, Douds GL, Hill K, Farace E: Transsphenoidal surgery for pituitary adenoma in elderly patients. Acta Neurochir (Wien) 150:571-574, 2008 
42. Sherlock M, Ayuk J, Tomlinson JW, Toogood AA, AragonAlonso A, Sheppard MC, et al: Mortality in patients with pituitary disease. Endocr Rev 31:301-342, 2010

43. Tabaee A, Placantonakis DG, Schwartz TH, Anand VK: Intrathecal fluorescein in endoscopic skull base surgery. Otolaryngol Head Neck Surg 137:316-320, 2007

44. Tanaka Y, Hongo K, Tada T, Sakai K, Kakizawa Y, Kobayashi S: Growth pattern and rate in residual nonfunctioning pituitary adenomas: correlations among tumor volume doubling time, patient age, and MIB-1 index. J Neurosurg 98:359-365, 2003

45. Tanweer O, Kalhorn SP, Snell JT, Wilson TA, Lieber BA, Agarwal N, et al: Epidural blood patch performed for severe intracranial hypotension following lumbar cerebrospinal fluid drainage for intracranial aneurysm surgery. Retrospective series and literature review. J Cerebrovasc Endovasc Neurosurg 17:318-323, 2015

46. Turner HE, Adams CB, Wass JA: Pituitary tumours in the elderly: a 20 year experience. Eur J Endocrinol 140:383-389, 1999

47. Turrentine FE, Wang H, Simpson VB, Jones RS: Surgical risk factors, morbidity, and mortality in elderly patients. J Am Coll Surg 203:865-877, 2006

48. Yunoue S, Tokimura H, Tominaga A, Fujio S, Karki P, Usui $S$, et al: Transsphenoidal surgical treatment of pituitary adenomas in patients aged 80 years or older. Neurosurg Rev 37:269-277, 2014

49. Zhan R, Ma Z, Wang D, Li X: Pure endoscopic endonasal transsphenoidal approach for nonfunctioning pituitary adeno- mas in the elderly: surgical outcomes and complications in 158 patients. World Neurosurg 84:1572-1578, 2015

50. Zwagerman NT, Shin S, Wang EW, Fernandez-Miranda JC, Snyderman $\mathrm{CH}$, Gardner PA: A prospective, randomized control trial for lumbar drain placement after endoscopic endonasal skull base surgery. J Neurol Surg B Skull Base 77:LFP-13-03, 2016 (Abstract)

\section{Disclosures}

The authors report no conflict of interest concerning the materials or methods used in this study or the findings specified in this paper.

\section{Author Contributions}

Conception and design: Wilson, Schwartz. Acquisition of data: Wilson, Omay, Schwartz. Analysis and interpretation of data: Wilson. Drafting the article: Wilson. Critically revising the article: Wilson, Schwartz. Reviewed submitted version of manuscript: all authors. Approved the final version of the manuscript on behalf of all authors: Wilson. Statistical analysis: Wilson. Study supervision: Schwartz.

\section{Correspondence}

Peter Wilson, Department of Neurosurgery, Prince of Wales Hospital, Barker St., Randwick NSW 2031, Australia. email: peterwilson27@gmail.com. 